\title{
Observing dyspnoea in others elicits dyspnoea, negative affect and brain responses
}

\author{
Michaela Herzog ${ }^{1,6}$, Josef Sucec ${ }^{1,6}$, Ilse Van Diest ${ }^{1}$, Omer Van den Bergh¹, \\ Cecile Chenivesse ${ }^{2}$, Paul Davenport ${ }^{3}$, Thomas Similowski ${ }^{4,5}$ and \\ Andreas von Leupoldt (1) ${ }^{1}$
}

Affiliations: ${ }^{1}$ Health Psychology, University of Leuven, Leuven, Belgium. ${ }^{2}$ Service de Pneumologie et ImmunoAllergologie, Université de Lille, INSERM, CHU Lille, Lille, France. ${ }^{3}$ Dept of Physiological Sciences, University of Florida, Gainesville, FL, USA. " Sorbonne Universités, UPMC Univ Paris 06, INSERM, UMRS1158 Neurophysiologie Respiratoire Expérimentale et Clinique, Paris, France. ${ }^{5}$ AP-HP, Groupe Hospitalier PitiéSalpêtrière Charles Foix, Service de Pneumologie et Réanimation Médicale (Département 'R3S'), Paris, France. ${ }^{6}$ Both authors contributed equally to this work.

Correspondence: Andreas von Leupoldt, Research Group Health Psychology, University of Leuven, Tiensestraat 102, 3000 Leuven, Belgium. E-mail: andreas.vonleupoldtakuleuven.be

@ERSpublications

Observing dyspnoea in other persons induces dyspnoea, negative affect and increased brain responses in the observer http://ow.ly/K9jD30i9Whs

Cite this article as: Herzog M, Sucec J, Van Diest I, et al. Observing dyspnoea in others elicits dyspnoea, negative affect and brain responses. Eur Respir J 2018; 51: 1702682 [https://doi.org/10.1183/ 13993003.02682-2017].

ABSTRACT Dyspnoea is usually caused by diagnosable cardiorespiratory mechanisms. However, frequently dyspnoea relates only weakly or not at all to cardiorespiratory functioning, suggesting that additional neuropsychosocial processes contribute to its experience. We tested whether the mere observation of dyspnoea in others constitutes such a process and would elicit dyspnoea, negative affect and increased brain responses in the observer.

In three studies, series of pictures and videos were presented, which either depicted persons suffering from dyspnoea or nondyspnoeic control stimuli. Self-reports of dyspnoea and affective state were obtained in all studies. Additionally, respiratory variables and brain responses during picture viewing (late positive potentials in electroencephalograms) were measured in one study.

In all studies, dyspnoea-related pictures and videos elicited mild-to-moderate dyspnoea and increased negative affect compared to control stimuli. This was paralleled by increased late positive potentials for dyspnoea-related pictures while respiratory variables did not change. Moreover, increased dyspnoea correlated modestly with higher levels of empathy in observers.

The present results demonstrate that observing dyspnoea in others elicits mild-to-moderate dyspnoea, negative affect, and increased brain responses in the absence of respiratory changes. This vicarious dyspnoea has clinical relevance, as it might increase suffering in the family and medical caregivers of dyspnoeic patients. 


\section{Introduction}

Dyspnoea is the aversive cardinal symptom in various prevalent diseases including respiratory, cardiac, cancerogenic, neuromuscular and psychological disorders [1,2], and is highly common in the general population [3]. It is frequently associated with increased negative affect [4], severe suffering [5], limited quality of life [6], high socioeconomic costs [7] and even increased mortality risk [8]. Dyspnoea is usually caused by cardiorespiratory mechanisms that can be objectively measured $[9,10]$. However, in many cases, dyspnoea relates only weakly or not at all to cardiorespiratory functioning or spirometric indices $[8,11,12]$. This suggests that additional psychological and social processes contribute to the experience of dyspnoea, which are ultimately integrated with cardiorespiratory signals within higher brain centres [13]. However, although this multifactorial nature of dyspnoea has long been recognised [10], the respective contributions of these neuropsychosocial processes remain poorly understood [9].

Notably, it has long been neglected that dyspnoea is typically experienced by patients within social contexts, such as in the presence of family members, friends, colleagues, other patients and medical caregivers. Consequently, these individuals become observers of the dyspnoea of others. While the suffering of the dyspnoeic patient in these situations seems obvious, nothing is known about the potential effects that the observation of dyspnoea in this patient causes in the observer.

Research on pain, a prevalent and aversive symptom that shares many similarities with dyspnoea [14-16], has demonstrated that observing others in pain consistently evokes negative affective reactions and can even induce the experience of pain in the observer $[17,18]$. This vicarious pain (i.e. a pain experience when observing others in pain in the absence of nociceptive input) is particularly prominent in more empathic observers [18] and is associated with objective changes in the observer's brain processing, as indicated by elevated late positive potentials in the electroencephalogram (EEG) [19, 20]. These late positive potentials are event-related brain potentials and reflect sustained affective processing and motivated attention during the observation of pain in others [21]. Whether the observation of dyspnoea would have similar effects and thus constitute a neuropsychosocial process contributing to the experience of dyspnoea has not yet been explored. If similar results were found for vicarious dyspnoea, such increases in dyspnoea and negative affect in caregivers of dyspnoeic patients might potentially contribute to the known high burden of caregivers [22-24].

Therefore, we examined in three studies the effects of observing dyspnoea in others. Specifically, we tested the hypothesis that watching series of pictures and videos depicting persons suffering from dyspnoea would elicit increased dyspnoea, negative affect and brain responses (late positive potentials) in the observer.

\section{Study 1}

\section{Material and methods}

\section{Participants}

86 students with normal hearing and vision (61 females; mean \pm SD age $19.13 \pm 1.65$ years) were tested. Study 1 and all subsequent studies were approved by the ethics committee of the University of Leuven (Leuven, Belgium) (study 1 and 2: G-2015-04-212; study 3: G-2016-02-484).

\section{Picture stimuli}

The stimuli consisted of 44 dyspnoea-related pictures spanning a sufficiently diverse range of scenes and five neutral control pictures to minimise participant load. The dyspnoea-related pictures were selected from self-made pictures and freely available sources and included scenes that depicted humans in dyspnoea-related situations (e.g. breathing through an oxygen mask, suffocating, drowning). The five neutral pictures (chair, mushroom, spoon, hammer and rolling pin) were taken from the International

Conflict of interest: T. Similowski reports personal fees from AstraZeneca, Boerhinger Ingelheim France, GSK, Lungpacer Inc., TEVA, Chiesi, Pierre Fabre and Invacare, and personal fees and non-financial support from Novartis, outside the submitted work. A. von Leupoldt received research grants STRT/13/002 and DBOF/14/021 from Research Fund KU Leuven, Belgium, research infrastructure grant AKUL/13/07 from Herculesstichting, Belgium, and long-term structural research funding Methusalem grant METH/15/011 from the Flemish Government, Belgium, during the conduct of the study.

Support statement: This study was supported by grants from the Research Fund KU Leuven, Belgium (STRT/13/002 and DBOF/14/021), by an infrastructure grant from the Herculesstichting, Belgium (AKUL/13/07), by the "Asthenes" long-term structural funding Methusalem grant (METH/15/011) by the Flemish Government, Belgium, and by the Investissement d'Avenir (ANR-10-AIHU 06) by the French Government, France. The funders had no role in the study design, data collection, data analysis, data interpretation or writing of the manuscript. M. Herzog, J. Sucec and A. von Leupoldt had full access to all data. All authors had the final responsibility for the decision to submit the manuscript for publication. Funding information for this article has been deposited with the Crossref Funder Registry. 
Affective Picture System (IAPS) [25] and were selected based on normative ratings confirming neutral affective valence and low arousal. All pictures were presented for $6 \mathrm{~s}$ at a resolution of $1024 \times 768$ pixels on a standard 15-inch monitor.

\section{Ratings of dyspnoea}

After each picture, participants rated their own perceived dyspnoea on an 11-point numerical rating scale ranging from 0 (no noticeable dyspnoea) to 10 (maximal imaginable dyspnoea). Prior to testing, dyspnoea was explained to the participants in all three studies as "difficult or uncomfortable breathing".

Ratings of affective valence and arousal

After each picture, the nine-point self-assessment manikin [26] was used by participants to rate their own affective state along a valence (range $1=$ unpleasant to $9=$ pleasant) and arousal (range $1=$ calm to $9=$ aroused) dimension.

\section{Procedure}

After providing written informed consent, participants received standardised instructions regarding the procedure and rating scales, followed by the presentation of the 44 dyspnoea-related and the five neutral pictures in random order. Each picture was followed by the ratings of dyspnoea, affective valence and arousal.

\section{Statistical analysis}

Data analysis for this and the subsequent studies was performed using IBM SPSS Statistics 24 (IBM, Armonk, NY, USA). The ratings for the dyspnoea-related and the neutral pictures were averaged for each participant for each picture category separately. Three paired t-tests were used to compare the group mean ratings of dyspnoea, affective valence and arousal between the dyspnoea-related and the neutral pictures. Nonparametric tests were applied in case of violations of assumptions [27]. A Bonferroni corrected level of significance of $\mathrm{p}<0.0167$ was applied to correct for the number of tests conducted.

\section{Results}

From the 86 tested participants, five were excluded due to technical failure $(n=1)$ or erratic rating response $(n=4)$, resulting in 81 participants for the final analysis. As presented in figure 1, participants reported significantly higher dyspnoea $(p<0.001)$ and affective arousal $(p<0.001)$ as well as lower affective valence $(\mathrm{p}<0.001)$ for the dyspnoea-related pictures compared to the neutral pictures.

\section{Study 2}

Material and methods

Participants

All participants from study 1 took part in study 2 as well.

\section{Video stimuli}

The stimuli consisted of five video sets each containing a neutral (e.g. boy using a computer), a negative (e.g. disabled boy having a seizure) and a dyspnoea-related video (e.g. boy having an asthma attack). The videos within each set were matched based on content. Furthermore, levels of affective valence and arousal were matched between the negative and dyspnoea-related video. Overall, each participant watched 15 videos in randomised order which allowed sufficient variation of scenes while minimising participant load. The video durations ranged from $42 \mathrm{~s}$ to $122 \mathrm{~s}$ (median $56 \mathrm{~s}$ ) with identical durations for the three videos within each video set. The videos were selected from self-made videos and freely available sources and were presented at a $1024 \times 768$ pixel resolution on a standard 15 -inch monitor. All videos contained sound, which was matched between videos based on decibel level (according to International Organization for Standardization 80000-3 standards) and was presented via headphones.

Ratings of dyspnoea

After each video, participants rated their own perceived dyspnoea in a similar manner to study 1 .

Ratings of affective valence and arousal

After each video, participants rated their own affective state in a similar manner to study 1.

\section{Procedure}

After providing written informed consent, participants received standardised instructions regarding the procedure and rating scales followed by the randomised presentation of the five video sets while wearing the headphones. Each video was followed by ratings of dyspnoea, affective valence and arousal. 

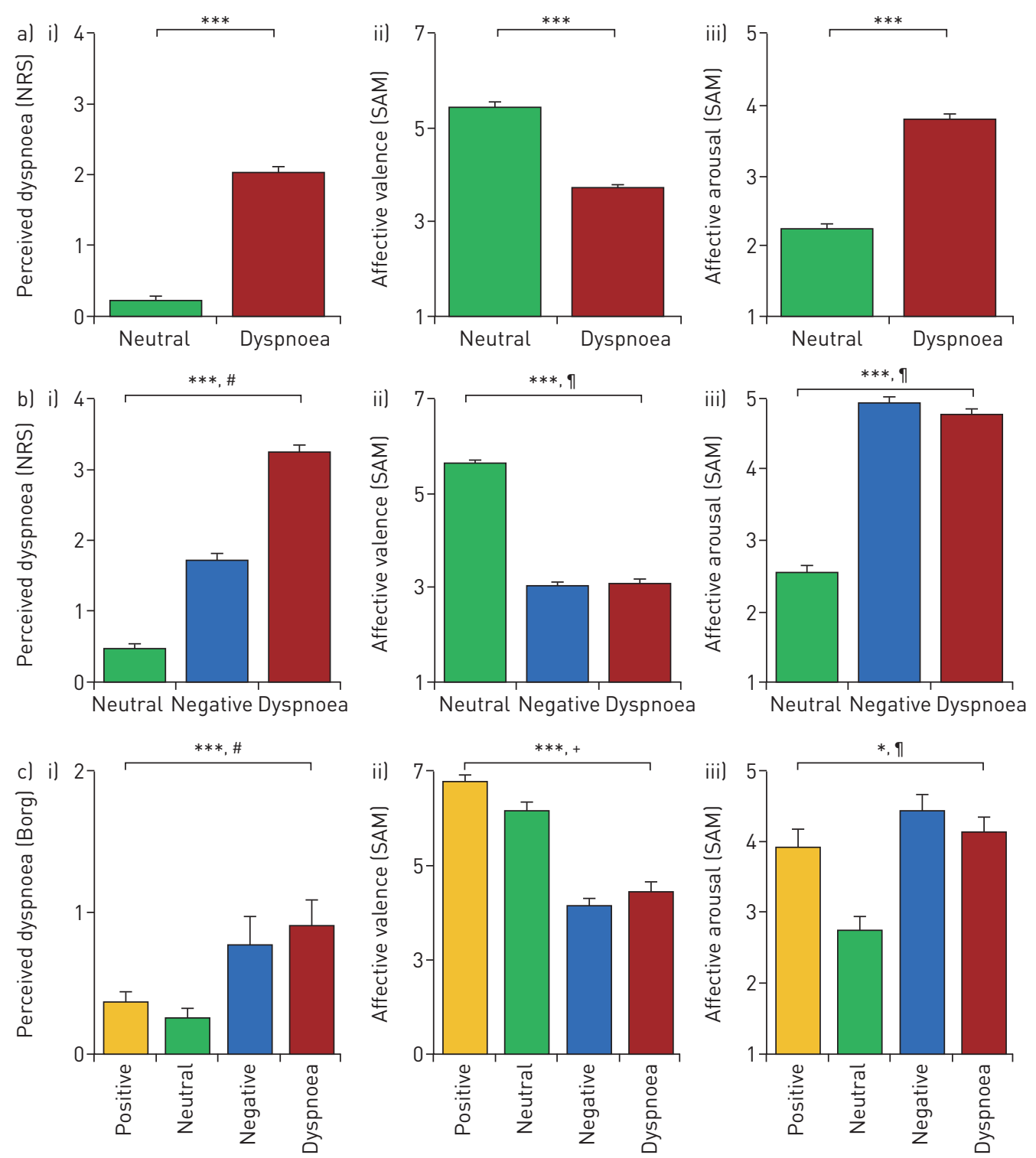

FIGURE 1 Mean \pm SE ratings of i) dyspnoea, ii) affective valence and iii) arousal upon viewing dyspnoea-related and control picture series (studies a) 1 and c) 3) and b) videos (study 2). In study 1 (pictures) and 2 (videos), dyspnoea was rated on a numerical rating scale (NRS) ranging from 0 (no noticeable dyspnoea) to 10 (maximal imaginable dyspnoea). In study 3 (pictures), dyspnoea was rated on a modified Borg scale ranging from 0 (no noticeable dyspnoeal to 10 (maximal imaginable dyspnoea). In all three studies, the self-assessment manikin (SAM) was used to rate affective valence (range 1 (unpleasant) to 9 (pleasant)) and affective arousal (range $1(\mathrm{calm})$ to 9 (aroused)). ${ }^{*}: p<0.05 ;{ }^{* * *}: p<0.001 .{ }^{\#}$ : significant positive linear trend; ${ }^{\text {ๆ: }}$ significant quadratic trend; ${ }^{+}$: significant negative linear trend.

\section{Statistical analysis}

The ratings for the neutral, negative and dyspnoea-related videos were averaged for each video category separately. Three repeated-measures ANOVAs with the within factor video category (neutral, negative and dyspnoea-related) were calculated to examine whether the ratings of dyspnoea, affective valence and arousal differed between the video categories. One a priori polynomial contrast for each outcome was calculated to investigate the trend. Based on previous literature [19,20], we expected a linear trend for the dyspnoea ratings (neutral $<$ negative $<$ dyspnoea-related) and a quadratic trend for the affective valence (neutral $>$ negative $=$ dyspnoea-related) and arousal ratings (neutral $<$ negative $=$ dyspnoea-related). A Bonferroni corrected level of significance of $\mathrm{p}<0.0167$ was applied to correct for the number of tests conducted.

\section{Results}

For study 2 the same 81 participants as in study 1 were included in the final analysis. Results for the ratings of dyspnoea, affective valence and arousal for the three video categories are presented in figure 1 . 
ANOVAs showed a significant difference between video categories for ratings of dyspnoea $(\mathrm{p}<0.001)$, affective valence $(\mathrm{p}<0.001)$ and arousal $(\mathrm{p}<0.001)$. The a priori polynomial contrasts revealed the expected significant linear trend for ratings of dyspnoea $(\mathrm{p}<0.001)$ with the lowest dyspnoea ratings for neutral videos, followed by negative videos, and the largest dyspnoea ratings for the dyspnoea-related videos. As expected, a significant quadratic trend was found for ratings of affective valence $(p<0.001)$ with the highest valence for the neutral videos and the lowest valence for both dyspnoea-related and negative videos. Similarly, the affective arousal ratings showed the expected quadratic trend $(\mathrm{p}<0.001)$ with the lowest arousal for neutral videos and highest arousal for both dyspnoea-related and negative videos.

\section{Study 3}

Material and methods

Participants

50 healthy participants (41 females) with normal hearing and vision were tested. Exclusion criteria based on self-report included any acute or chronic disease, insufficient pulmonary function, alcohol or drug intoxication, nicotine or caffeine consumption $24 \mathrm{~h}$ prior to testing, or pregnancy. Additionally, participants from study 1 and 2 were excluded from participating in study 3. Adequate pulmonary function (forced expiratory volume in $1 \mathrm{~s}>80 \%$ predicted) was confirmed prior to testing by standard spirometry [28]. Characteristics of participants are presented in table 1 [29].

\section{Picture stimuli}

The 40 dyspnoea-related pictures from study 1 with the highest dyspnoea ratings were selected for study 3 and matched to 40 neutral (e.g. affectively neutral persons), 40 positive (e.g. smiling/happy persons) and 40 negative pictures (e.g. crying/aggressive persons) from the IAPS [25]. Matching was based on normative ratings for affective valence, arousal, picture content and picture composition. This resulted in four picture series, each containing 40 pictures of the same category (neutral, positive, negative or dyspnoea-related) that were presented at a $2560 \times 1440$ pixel resolution on a standard 32 -inch monitor in randomised order. Each picture was presented for $4 \mathrm{~s}$ followed by a jittered fixation cross (mean (range) interstimulus interval $2.0(1.8-2.2) \mathrm{s})$, resulting in a total duration of $4 \mathrm{~min}$ per picture series.

\section{Ratings of dyspnoea}

After each picture series, participants rated their own perceived dyspnoea during picture viewing on a modified Borg scale [30] ranging from 0 (no noticeable dyspnoea) to 10 (unbearable dyspnoea).

\section{Affective valence and arousal}

After each picture series, participants rated their own affective state in a similar manner to study 1 and 2.

\section{Assessment of individual levels of empathy}

The Dutch version of the well-validated interpersonal reactivity index [31] was used as an established measure of empathy. This questionnaire contains 28 items that are rated on a five-point scale ranging from "does not describe me well" (0) to "describes me very well" (4) with higher scores indicating higher levels of empathy.

\section{Assessment of individual levels of anxiety}

In order to explore potential effects of anxiety, which has been shown to interact with the perception of dyspnoea in previous studies [32-35], the Dutch trait version of the state-trait anxiety inventory [36] was

\section{TABLE 1 Characteristics of participants in study 3}

Female/male
Age years
Height $\mathrm{cm}$
Weight kg
FEV1 $L^{\#}$
FEV $1 \%$ pred $^{\#}$
FVC L
FVC $\%$ pred
Interpersonal Reactivity Index score
Trait version State-Trait Anxiety Inventory score

Data are presented as $\mathrm{n}$ or mean \pm SD. $F E V 1$ : forced expiratory volume in $1 \mathrm{~s}$; FVC: forced vital capacity.

\#: norm values based on American Thoracic Society guidelines [29]. 

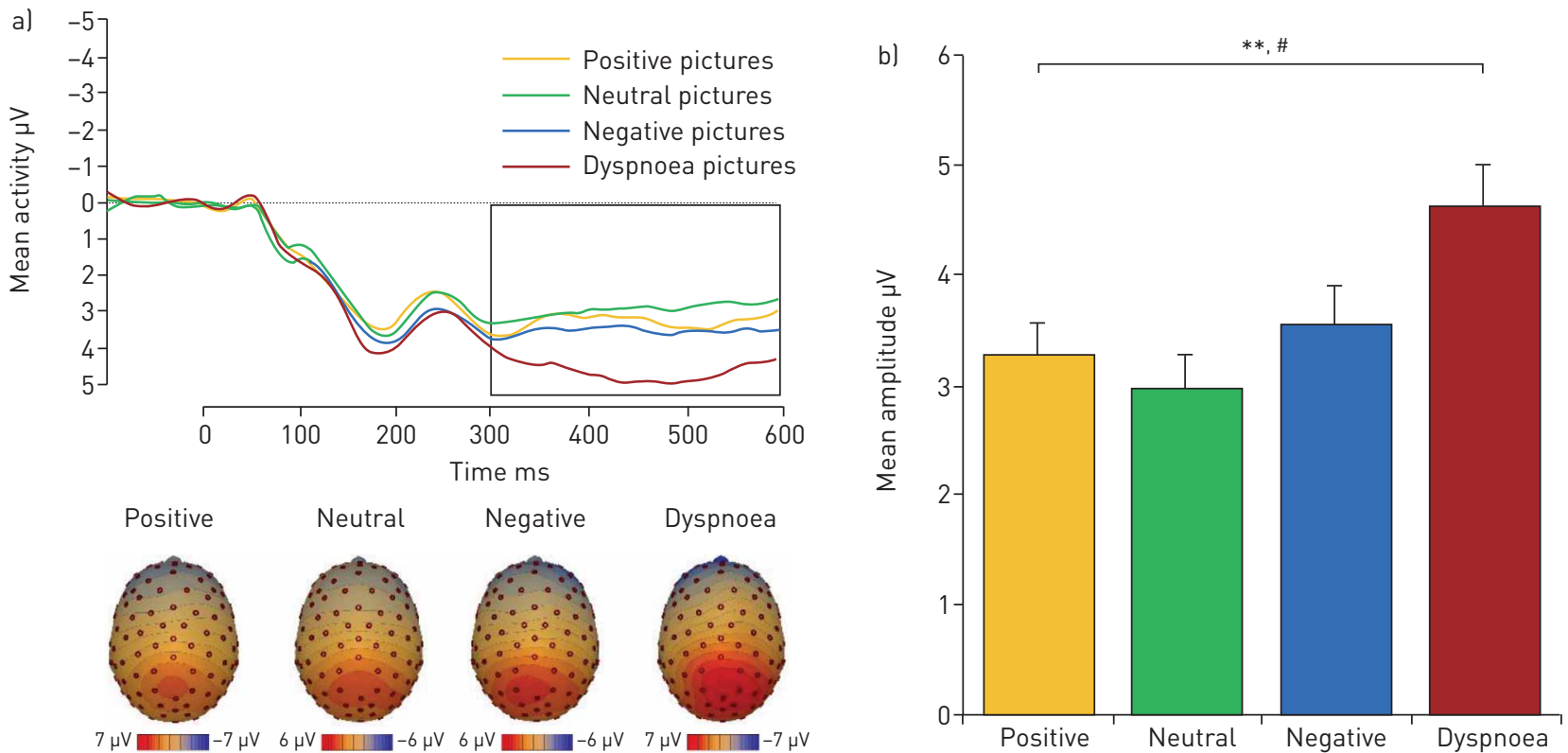

FIGURE 2 Brain responses during picture viewing in study 3. a) Averaged waveforms of late positive potentials evoked by positive, neutral, negative and dyspnoea-related pictures. The frame indicates the latency of the late positive potentials ranging from $300 \mathrm{~ms}$ to $600 \mathrm{~ms}$ after picture onset derived from sensors at centroparietal scalp positions (red areas in the scalp topography plots) with corresponding scalp topographies. b) Mean \pm SE amplitudes of the late positive potential (300-600 ms) for the positive, neutral, negative and dyspnoea-related pictures. ${ }^{* *}$ : $p<0.01$. \#: significant positive linear trend.

used. This widely used questionnaire consists of 20 items that are rated on a four-point scale ranging from "almost never" (1) to "almost always" (4), with higher scores indicating higher trait anxiety levels.

\section{Respiratory variables}

Respiratory variables were measured during picture presentation in 24 randomly assigned participants from the whole sample. This subgroup of participants breathed through a breathing circuit while wearing a nose clip. The breathing circuit was connected to a two-way nonrebreathing valve (Hans Rudolph, Shawnee, KS, USA), where mouth pressure was sampled. The inspiratory port of the nonrebreathing valve was connected to a pneumotachograph (Hans Rudolph) measuring inspiratory airflow. Respiratory variables including breathing frequency $(f)$, inspiratory time $(t \mathrm{I})$, tidal volume $(V T)$, minute ventilation $\left(V^{\prime} \mathrm{E}\right)$, mean airflow $\left(V^{\prime}\right)$ and peak inspiratory mouth pressure $\left(P_{\mathrm{I}}\right)$ were measured continuously. Respiratory variables were only measured in a subgroup of 24 participants in order to allow the additional exploration of 1) whether the picture category would influence respiratory behaviour and 2) whether breathing through a breathing circuit would influence ratings as well as brain responses in the EEG.

\section{EEG and data reduction}

The 129-channel EEG was continuously recorded (Philips Electrical Geodesics, Eugene, OR, USA) with a sampling rate of $250 \mathrm{~Hz}$ and central-midline $(\mathrm{CZ})$ as the reference electrode. Impedance was maintained at $<50 \mathrm{k} \Omega$. EEG data were processed offline using BESA Research 6.0 (BESA, Gräfelfing, Germany). After data filtering (high-pass filter $0.1 \mathrm{~Hz}$, low-pass filter $30 \mathrm{~Hz}$ and notch filter $50 \mathrm{~Hz}$ ) and correction and/or removal of artefacts (i.e. eye blinks), data were re-referenced to the original average reference. Epochs of interest were extracted $100 \mathrm{~ms}$ before and $1200 \mathrm{~ms}$ after picture onset and averaged across the 40 pictures of each category. Late positive potentials were identified from $300-600 \mathrm{~ms}$ after picture onset in the centroparietal region (electrodes 61, 62, 72 and 78) (figure 2a). The mean amplitude across the electrodes of interest was calculated and entered into the analysis.

\section{Procedure}

After providing written informed consent, participants underwent standard spirometry, filled out the questionnaires and received standardised instructions and explanations regarding the experimental procedure. After attaching the EEG net, the four picture series were presented, each followed by ratings of dyspnoea, affective valence and arousal. The order of picture series was counterbalanced across participants. 
Statistical analysis

The ratings for the neutral, positive, negative and dyspnoea-related pictures were averaged for each picture category separately. Four mixed ANOVAs with the within factor picture category (positive, neutral, negative and dyspnoea-related) and the between-factor breathing circuit (breathing through the breathing circuit or not) were calculated for ratings of dyspnoea, affective valence and arousal as well as for late positive potentials. One a priori test was conducted per outcome using polynomial contrasts. Based on previous literature $[19,20]$, we expected a linear trend for the dyspnoea (positive $<$ neutral < negative < dyspnoea-related) and the affective valence ratings (positive $>$ neutral $>$ negative $=$ dyspnoea-related) and a quadratic trend for arousal (neutral $<$ positive $=$ negative $=$ dyspnoea-related). For each respiratory variable, a repeated-measures ANOVA was calculated with the within-factor picture category (positive, neutral, negative and dyspnoea-related). For the ANOVAs, a Bonferroni corrected level of significance of $\mathrm{p}<0.0125$ was used to correct for the number of conducted tests for our main outcomes. Finally, the association between empathy as well as trait anxiety and dyspnoea ratings for the dyspnoea-related picture series was investigated using correlation analysis (Spearman's $\rho, p<0.05$ ).

\section{Results}

Ratings

Results for the ratings of dyspnoea, affective valence and arousal for the four picture series are presented in figure 1. Ratings of dyspnoea differed significantly between the picture categories $(\mathrm{p}<0.001)$. The polynomial contrast showed the expected significant linear trend $(\mathrm{p}<0.001)$ with the lowest dyspnoea ratings for neutral and positive pictures, followed by negative pictures, and the highest dyspnoea ratings for the dyspnoea-related pictures. A modest, but significant correlation was found between empathy levels and the ratings of dyspnoea during watching the dyspnoea-related pictures $(\rho=0.27, p=0.030)$, whereas no correlation was observed with trait anxiety levels $(\rho=0.15, p=0.289)$.

In addition, ratings of affective valence differed significantly between the picture categories $(\mathrm{p}<0.001)$. The polynomial contrast showed the expected significant linear trend $(\mathrm{p}<0.001)$ with the highest affective valence for positive pictures, followed by neutral pictures, and the lowest affective valence for dyspnoea-related and negative pictures.

A significant difference between the picture categories was found for ratings of affective arousal $(\mathrm{p}=0.001)$. The polynomial contrast demonstrated the expected significant quadratic trend $(p=0.010)$ with highest affective arousal ratings for negative, dyspnoea-related and positive pictures and the lowest affective arousal ratings for the neutral pictures.

The breathing circuit had no significant effect on ratings of dyspnoea $(\mathrm{p}=0.223)$, affective valence $(\mathrm{p}=0.336)$ or arousal $(\mathrm{p}=0.972)$.

\section{Respiratory variables}

For the subgroup in which respiratory variables were measured, no significant differences between the picture categories were observed in any variable $\left(f, t \mathrm{I}, V_{\mathrm{T}}, V^{\prime} \mathrm{E}, V^{\prime}\right.$ and $\left.P_{\mathrm{I}}\right)($ table 2$)$.

\section{Late positive potentials}

For the late positive potentials, a significant difference was found between the picture categories $(\mathrm{p}<0.001)$. The polynomial contrast showed the expected significant linear trend $(p<0.001)$ with the largest late positive potentials for the dyspnoea-related pictures, followed by decreasing late positive potentials for negative, positive and neutral pictures (figure $2 \mathrm{~b}$ ). The breathing circuit had no significant effect on the late positive potentials $(\mathrm{p}=0.246)$.

\section{Discussion}

The present work aimed at investigating the phenomenon of vicarious dyspnoea by studying the effects of watching dyspnoea-related pictures and videos on the observer. The consistent results from three studies firstly demonstrate that merely observing dyspnoea in others induces an experience of mild-to-moderate dyspnoea in the observer to a greater extent than visual control stimuli in the absence of any experimental dyspnoea induction (e.g. by exercise, resistive loads or carbon dioxide). This was paralleled by increased negative affect and increased brain responses as indicated by larger late positive potentials during watching dyspnoea-related pictures. Moreover, increases in vicarious dyspnoea were modestly related to higher levels of empathy in the observer, but were unrelated to objective indices of breathing and trait anxiety levels. Together, these findings demonstrate that vicarious dyspnoea does exist in a manner similar to vicarious pain and constitutes a neuropsychosocial process that contributes to the experience of dyspnoea in the absence of respiratory changes and physiological dysfunction. This supports recent views that central brain processes alone can elicit or significantly intensify the experience of dyspnoea [37-39]. 
TABLE 2 Respiratory variables during viewing the positive, neutral, negative and dyspnoea-related picture series for the subgroup of subjects breathing through the breathing circuit in study 3

\begin{tabular}{|c|c|c|c|c|c|}
\hline & Positive & Neutral & Negative & Dyspnoea & p-values \\
\hline Breathing frequency breaths $\cdot \min ^{-1}$ & $12.17 \pm 3.57$ & $12.19 \pm 3.25$ & $11.88 \pm 3.06$ & $12.23 \pm 3.61$ & 0.539 \\
\hline Inspiratory time s & $2.23 \pm 0.47$ & $2.24 \pm 0.56$ & $2.23 \pm 0.48$ & $2.23 \pm 0.57$ & 0.974 \\
\hline Tidal volume $\mathrm{mL} \cdot \mathrm{kg}^{-1}$ & $10.61 \pm 2.48$ & $10.68 \pm 2.28$ & $10.84 \pm 2.52$ & $10.64 \pm 2.12$ & 0.903 \\
\hline Minute ventilation $\mathrm{mL} \cdot \mathrm{kg}^{-1}$ & $123.64 \pm 26.46$ & $126.35 \pm 30.97$ & $124.73 \pm 29.92$ & $125.47 \pm 27.30$ & 0.862 \\
\hline Mean airflow L.s ${ }^{-1}$ & $0.23 \pm 0.05$ & $0.24 \pm 0.07$ & $0.24 \pm 0.06$ & $0.24 \pm 0.05$ & 0.804 \\
\hline Peak inspiratory mouth pressure $\mathrm{cmH}_{2} \mathrm{O}$ & $-1.38 \pm 0.23$ & $-1.40 \pm 0.20$ & $-1.40 \pm 0.22$ & $-1.39 \pm 0.21$ & 0.664 \\
\hline
\end{tabular}

Data are presented as mean $\pm S D$, unless otherwise stated. $n=24$.

The present findings are in line with several previous studies which showed that psychological factors such as negative affect and anxiety can intensify dyspnoea without corresponding respiratory changes [32, 33, 35]. For example, LIVERMORE et al. [33] demonstrated in the absence of any respiratory differences that chronic obstructive pulmonary disease (COPD) patients suffering from panic attacks showed increased sensitivity to experimentally induced dyspnoea compared to COPD patients without panic attacks and healthy controls.

Moreover, the present findings converge with comparable results in pain research, which showed that seeing somebody else in pain can induce pain [17], negative affect [20] and increased neural processing in the observer [18-20]. For example, Osborn and Derbyshire [17] found that pain-related pictures and videos elicited vicarious pain and negative affect, which were of comparable magnitudes to those in the present study and were associated with higher levels of empathy. Similarly, studies using EEG methodology showed that pictures and videos featuring pain-related faces elicited stronger negative affect and larger late positive potentials compared to control stimuli $[19,20]$.

Although the present studies were able to demonstrate vicarious dyspnoea in self-report and neural processing, the specific brain mechanisms underlying these findings remain unclear. However, for vicarious pain, several theories have suggested respective mechanisms. A prominent example is the perception-action model of empathy [40], proposing that the neural basis for empathy are mirror neurons, which are triggered when another person is seen in pain. These automatically activate a shared representation in the brain, which evokes pain in the observer. Given the observed associations of vicarious dyspnoea with empathy levels in the present study 3, it might be assumed that a similar mechanism is activated when seeing another person experiencing dyspnoea. However, future neuroimaging studies will be required to further investigate this hypothesis.

The present findings are clinically highly relevant, because large numbers of family members, friends, colleagues, other patients and medical caregivers regularly observe the dyspnoea of others in their professional and/or private everyday lives. This exposure to the dyspnoea of others could potentially elicit vicarious dyspnoea and negative affect in these individuals and lead to increased suffering, especially if they are more empathic. This is particularly relevant for caregivers of dyspnoeic patients, who already have a documented high level of burden and are at elevated risk for developing (psychological) disorders. Vicarious dyspnoea and related negative affect might contribute to an even higher burden in these caregivers and further increase their risk of developing (psychological) disorders [22-24]. Furthermore, vicarious dyspnoea might influence the frequency of emergency calls by caregivers for the patient in care [22]. This necessitates future studies on vicarious dyspnoea in these caregivers. However, in a more positive vein, vicarious dyspnoea elicited by pictures, videos or even imaginary training [41] might be used in cognitive-behaviourally oriented interventions to desensitise those patients who (due to high levels of anticipatory fear of dyspnoea) avoid dyspnoea-related situations such as physical activities [42, 43]. Similarly, vicarious dyspnoea might also be applied in the training of caregivers, who frequently underestimate dyspnoea in patients [44, 45]. Improving their accuracy in estimating patients' dyspnoea levels might be a fruitful strategy to reduce unnecessary patient suffering. This could be particularly important for patients who are unable to indicate their own dyspnoea, e.g. in intensive care unit settings.

When interpreting the present results, certain limitations must be considered. Our samples consisted mostly of young, healthy, predominantly female students, which might limit the generalisability of our findings to other populations. To investigate potential sex effects, future studies should aim for a more balanced sex distribution. Moreover, we did not investigate participants' family histories of respiratory 
disorders, which could have influenced their vicarious dyspnoea due to differences in previous occasions of observing dyspnoea. Furthermore, we did not examine the effects of vicarious dyspnoea in caregivers of dyspnoeic patients, who would most likely report even higher vicarious dyspnoea, due to omnipresent dyspnoea in their role as caregiver. Finally, in study 3 (using a modified Borg scale) somewhat less perceived dyspnoea was reported than in study 1 and 2 (using a numerical rating scale with different anchors). This might not indicate less perceived dyspnoea in study 3 per se, but rather might reflect the use of a different scale [46], which necessitates future studies comparing the effects of vicarious dyspnoea when using different rating instruments of dyspnoea.

In conclusion, the present results demonstrate that observing dyspnoea in others elicits mild-to-moderate dyspnoea, negative affect and increased brain responses in the absence of respiratory changes and physiological dysfunction. Future studies are required to directly examine the potential clinical effects of vicarious dyspnoea in caregivers of dyspnoeic patients.

Author contributions: A. von Leupoldt, P. Davenport, C. Chenivesse, T. Similowski, O. Van den Bergh, I. Van Diest, J. Sucec and M. Herzog conceptualised the research design and research protocol. M. Herzog, J. Sucec, P. Davenport, C. Chenivesse, T. Similowski and A. von Leupoldt were involved in making and collecting the stimuli material. J. Sucec, M. Herzog and A. von Leupoldt searched the literature. M. Herzog and J. Sucec were responsible for the data collection. M. Herzog, J. Sucec and A. von Leupoldt were responsible for the statistical analysis. M. Herzog, J. Sucec and A. von Leupoldt had access to all the data in the study and take responsibility for the integrity of the data as well as the data analysis. M. Herzog and J. Sucec created the figures. J. Sucec, M. Herzog and A. von Leupoldt wrote the manuscript. J. Sucec, M. Herzog, A. von Leupoldt, I. Van Diest, O. Van den Bergh, T. Similowski, C. Chenivesse and P. Davenport provided feedback on the protocol, interpretation of the study results, and on the manuscript. M. Herzog and J. Sucec contributed equally to this work. All authors read and approved the final version.

\section{References}

1 Smoller JW, Pollack MH, Otto MW, et al. Panic anxiety, dyspnea, and respiratory disease. Theoretical and clinical considerations. Am J Respir Crit Care Med 1996; 154: 6-17.

2 Solano JP, Gomes B, Higginson IJ. A comparison of symptom prevalence in far advanced cancer, AIDS, heart disease, chronic obstructive pulmonary disease and renal disease. J Pain Symptom Manage 2006; 31: 58-69.

3 Grønseth R, Vollmer WM, Hardie JA, et al. Predictors of dyspnoea prevalence: results from the BOLD study. Eur Respir J 2014; 43: 1610-1620.

4 Yohannes AM, Willgoss TG, Baldwin RC, et al. Depression and anxiety in chronic heart failure and chronic obstructive pulmonary disease: prevalence, relevance, clinical implications and management principles. Int $J$ Geriatr Psychiatry 2010; 25: 1209-1221.

5 Bausewein C, Booth S, Gysels $\mathrm{M}$, et al. Understanding breathlessness: cross-sectional comparison of symptom burden and palliative care needs in chronic obstructive pulmonary disease and cancer. J Palliat Med 2010; 13: 1109-1118.

6 Voll-Aanerud M, Eagan TML, Wentzel-Larsen T, et al. Changes in respiratory symptoms and health-related quality of life. Chest 2007; 131: 1890-1897.

7 Britton M. The burden of COPD in the UK: results from the Confronting COPD survey. Respir Med 2003; 97: S71-S79.

8 Figarska SM, Boezen HM, Vonk JM. Dyspnea severity, changes in dyspnea status and mortality in the general population: the Vlagtwedde/Vlaardingen study. Eur J Epidemiol 2012; 27: 867-876.

9 Laviolette L, Laveneziana P, ERS Research Seminar Faculty. Dyspnoea: a multidimensional and multidisciplinary approach. Eur Respir J 2014; 43: 1750-1762.

10 Parshall MB, Schwartzstein RM, Adams L, et al. An official American Thoracic Society statement: update on the mechanisms, assessment, and management of dyspnea. Am J Respir Crit Care Med 2012; 185: 435-452.

11 Heyse-Moore L, Beynon T, Ross V. Does spirometry predict dyspnoea in advanced cancer? Palliat Med 2000; 14: 189-195.

12 Mahler DA, Ward J, Waterman LA, et al. Longitudinal changes in patient-reported dyspnea in patients with COPD. COPD 2012; 9: 522-527.

13 Hayen A, Herigstad M, Pattinson KTS. Understanding dyspnea as a complex individual experience. Maturitas 2013; 76: 45-50.

14 Banzett RB, Moosavi SH. Dyspnea and pain: similarities and contrasts between two very unpleasant sensations. APS Bull 2001; 11: 1-8.

15 Morélot-Panzini C, Demoule A, Straus C, et al. Dyspnea as a noxious sensation: inspiratory threshold loading may trigger diffuse noxious inhibitory controls in humans. J Neurophysiol 2007; 97: 1396-1404.

16 von Leupoldt A, Sommer T, Kegat S, et al. Dyspnea and pain share emotion-related brain network. Neuroimage 2009; 48: 200-206.

17 Osborn J, Derbyshire SWG. Pain sensation evoked by observing injury in others. Pain 2010; 148: 268-274.

18 Singer T, Seymour B, O'Doherty J, et al. Empathy for pain involves the affective but not sensory components of pain. Science 2004; 303: 1157-1162.

19 González-Roldan AM, Martínez-Jauand M, Muñoz-García MA, et al. Temporal dissociation in the brain processing of pain and anger faces with different intensities of emotional expression. Pain 2011; 152: 853-859.

20 Reicherts P, Wieser MJ, Gerdes ABM, et al. Electrocortical evidence for preferential processing of dynamic pain expressions compared to other emotional expressions. Pain 2012; 153: 1959-1964.

21 Hajcak G, MacNamara A, Olvet DM. Event-related potentials, emotion, and emotion regulation: an integrative review. Dev Neuropsychol 2010; 35: 129-155. 
22 Gysels $\mathrm{MH}$, Higginson IJ. Caring for a person in advanced illness and suffering from breathlessness at home: threats and resources. Palliat Support Care 2009; 7: 153-162.

23 Nakken N, Janssen DJA, van den Bogaart EHA, et al. Informal caregivers of patients with COPD: home sweet home? Eur Respir Rev 2015; 24: 498-504.

24 Simpson AC, Rocker GM. Advanced chronic obstructive pulmonary disease: impact on informal caregivers. J Palliat Care 2008; 24: 49-54.

25 Lang PJ, Bradley MM, Cuthbert BN. International Affective Picture System (IAPS): Affective Ratings of Pictures and Instruction Manual. Tech Rep - 8. Gainesville, FL, University of Florida, 2008.

26 Bradley MM, Lang PJ. Measuring emotion: the self-assessment manikin and the semantic differential. $J$ Behav Ther Exp Psychiatry 1994; 25: 49-59.

27 Field A. Discovering Statistics Using SPSS. 3rd Edn. London, Sage, 2009.

28 Miller MR, Hankinson J, Brusasco V, et al. Standardisation of spirometry. Eur Respir J 2005; 26: 319-338.

29 Crapo RO, Hankinson JL, Irvin C, et al. Standardization of spirometry: 1994 update. Am J Respir Crit Care Med 1995; 152: 1107-1136.

30 Borg G. Psychophysical bases of perceived exertion. Med Sci Sports Exerc 1982; 14: 377-381.

31 De Corte K, Buysse A, Verhofstadt LL, et al. Measuring empathic tendencies: reliability and validity of the Dutch version of the interpersonal reactivity index. Psychol Belg 2007; 47: 235-260.

32 Lavietes $\mathrm{MH}$, Sanchez CW, Tiersky LA, et al. Psychological profile and ventilatory response to inspiratory resistive loading. Am J Respir Crit Care Med 2000; 161: 737-744.

33 Livermore N, Butler JE, Sharpe L, et al. Panic attacks and perception of inspiratory resistive loads in chronic obstructive pulmonary disease. Am J Respir Crit Care Med 2008; 178: 7-12.

34 Vinckier F, Morélot-Panzini C, Similowski T. Dyspnoea modifies the recognition of fearful expressions by healthy humans. Eur Respir J 2018; 51: 1702253.

35 von Leupoldt A, Van den Bergh O, Davenport PW. Anxiety, depression, and panic. In: DA Mahler, DE O’Donnell, eds. Dyspnea: Mechanisms, Measurement, and Management. 3rd Edn. Boca Raton, CRC Press, 2014; pp. 129-143.

36 van der Ploeg. De Zelf-Beoordelings Vragenlijst (STAI-DY). [The development and validation of a Dutch inventory for the measurement of anxiety: "de Zelf-Beoordehngs Vragenhjst (STAI-DY)"]. Tijdschr Voor Psychiatr 1982; 24: 576-588.

37 Herigstad M, Hayen A, Evans E, et al. Dyspnea-related cues engage the prefrontal cortex. Chest 2015; 148: 953-961.

38 Van den Bergh O, Witthöft M, Petersen S, et al. Symptoms and the body: taking the inferential leap. Neurosci Biobehav Rev 2017; 74: 185-203.

39 von Leupoldt A, Sommer T, Kegat S, et al. The unpleasantness of perceived dyspnea is processed in the anterior insula and amygdala. Am J Respir Crit Care Med 2008; 177: 1026-1032.

40 Preston SD, de Waal FB. Empathy: its ultimate and proximate bases. Behav Brain Sci 2002; 25: 1-20.

41 Dunsky A, Dickstein R, Marcovitz E, et al. Home-based motor imagery training for gait rehabilitation of people with chronic poststroke hemiparesis. Arch Phys Med Rehabil 2008; 89: 1580-1588.

42 Livermore N, Dimitri A, Sharpe L, et al. Cognitive behaviour therapy reduces dyspnoea ratings in patients with chronic obstructive pulmonary disease (COPD). Respir Physiol Neurobiol 2015; 216: 35-42.

43 von Leupoldt A. Treating anxious expectations can improve dyspnoea in patients with COPD. Eur Respir J 2017; 50: 1701352 .

44 Binks AP, Desjardin S, Riker R. ICU clinicians underestimate breathing discomfort in ventilated subjects. Respir Care 2017; 62: 150-155.

45 Haugdahl HS, Storli SL, Meland B, et al. Underestimation of patient breathlessness by nurses and physicians during a spontaneous breathing trial. Am J Respir Crit Care Med 2015; 192: 1440-1448.

46 Johnson MJ, Close L, Gillon SC, et al. Use of the modified Borg scale and numerical rating scale to measure chronic breathlessness: a pooled data analysis. Eur Respir J 2016; 47: 1861-1864. 